\title{
Developing and Validating an Obesity Bias for Students of Health Sciences in Turkey
}

\author{
Aydan Ercan*, Mehtap Akcil OK, Gul Kiziltan and Simay Altun \\ Department of Nutrition and Dietetics, Trakya University, Turkey \\ *Corresponding Author: Aydan Ercan, Department of Nutrition and Dietetics, \\ Trakya University, Turkey.
}

Received: March 19, 2021

Published: March 25, 2021

(C) All rights are reserved by Aydan Ercan., et al.

\begin{abstract}
Background: The biased attitudes and behaviors of healthcare professionals towards individuals with obesity cause these individuals to not be able to benefit from health services adequately. Awareness of factors that limit the quality of treatment will improve obesity treatment outcomes. This study aimed to develop a tool for measuring the obesity bias of health students.

Methods: 265 students who voluntarily participated in the study were asked to write 3 positive or negative definitions about individuals with obesity. These sentences were evaluated, the draft scale which consisted of 36 items was redesigned by the experts for the final edition. The scale was administered to 236 health sciences students. After correlation analysis of the items, 8 items were found to break the integrity of the Likert-type scale and reduced its reliability. And 1 item was neither positive nor negative.

Results: The Cronbach's alpha coefficient of the scale was found as 0.847 , which indicated that the developed scale was highly reliable. The one-dimension construct of the scale was validated by confirmatory factor analysis.

Conclusion: This scale, which the researchers call "Obesity Bias Scale", has been found to be a reliable tool that can be used to detect obesity bias.
\end{abstract}

Keywords: Obesity; Obesity Bias; Likert Scale; Validity Analysis; Reliability Analysis

\section{Introduction}

Causing various metabolic and systemic diseases, obesity has become a threat to society in recent years in all aspects as a result of its high prevalence, low treatment success, and high treatment costs. Majority of the studies on obesity consist of physiological and biochemical clinical studies. Nevertheless, obesity is not only physiological and psychological in nature, but also needs to be addressed socially due to biased, discriminatory or stigmatizing behavior of other individuals in the society against obesity [1-5]. The most common causes of social and psychological problems include bias and discrimination [5]. Bias is generally known as a negative attitude towards a group of people or individual members of a group emerging as a result of an incomplete/incorrect judgment process. Obesity bias, on the other hand, is defined as exposure to unequal opportunities in education and employment and negative attitudes and behaviors in health services (e.g., obese people are lazy, undisciplined) $[1,2,6]$. There is growing scientific evidence that obesity bias is becoming common among children and adults worldwide [5]. This situation negatively impacts the individuals with obesity of society in almost all areas of social life, including especially employment, education, and health $[7,8]$. For individuals with obesity, facing obesity bias, which they are susceptible to, especially in the field of health is a worrying problem. Individuals with obesity state that they feel the bias shown towards them when 
receiving health care and that they generally do not want to continue treatment because of negative attitudes towards them $[9,10]$. On the other hand, healthcare workers acknowledge that they exhibit negative attitudes and behaviors towards people with obesity. Common stereotypes reported among healthcare workers include attitudes that patients with obesity are lazy, weak-willed, and incompatible and unsuccessful with treatment [9,11-14].

The prevalence of obesity bias has been reported to reach up to $66 \%$ in the last 10 years in the United States and the European Union countries $[9,10]$. No studies or statistical report on this issue have been found in Turkey.

Given the serious consequences of obesity bias and its prevalence in healthcare professions, the need for developing effective and theoretically oriented interventions against obesity bias is well justified [11]. Creating awareness to prevent or reduce the emergence of obesity bias particularly in the health field will be the most important step. Creating awareness in the early period of health students as well as healthcare workers will increase the efficiency of measures taken to prevent obesity bias. Although obesity bias is an important problem, there is no scale to evaluate this situation.

\section{Aim of the Study}

The present study aimed to develop and validate a questionnaire to measure of obesity bias for health sciences students in Turkey.

\section{Methods}

The Likert-type scale is the most widely used multi-item scale developed to measure any attitudes, behaviors, thoughts, or bias. This type of scale is a data collection tool that helps determine the views of individuals and their level of agreement on the related phrases/ statements/ items. As there are many items in the scale, the score of an individual varies by how many of these items the individual agrees on or are responded correctly. A score that is obtained from a Likert-type scale or from a scale that conforms "Summated Rating Scale" technique is generally made up of the sum of the weights of the responses shown to the items in the scale $[15,16]$. Due to the reasons cited above, the "Obesity Bias Scale" was designed in Likert-type. The following steps were followed in the development of this scale.

All procedures performed in studies involving human participants were in accordance with the ethical standards of the insti- tutional and/or national research committee and with the 1964 Declaration of Helsinki and its later amendments or comparable ethical standards. This study was approved by Baskent University Institutional Review Board (Project no: KA14/347).

\section{Development of obesity bias scale}

- Stage 1: The study was launched with a total of 265 students who are studying in the Architecture, Nutrition and Dietetics, and Economics Departments of a university to determine the feelings, thoughts, attitudes, and biases related to obesity that is common in the society. These students were asked to write at least two statements expressing their positive or negative thoughts about individuals with obesity who were in the course at the time.

- $\quad$ Stage 2: The statements written by the students were read by the experts one by one and those which could be used as bias statements were determined. Also considering the experiences, they had gained about individuals with obesity along their professional life, the researchers edited these statements in accordance with item writing rules of the scale. The same and/or similar statements collected from the students were removed from the list, and therefore, a 40 item draft list was formed.

- Stage 3: The corrected and rewritten statements of bias were evaluated considering the principles of Likert-type scale development. In this process, the number of positive and negative statements/items was made approximately equal. The items at this stage were submitted to expert opinions in terms of language and content.

- $\quad$ Stage 4: The draft list was re-administered to approximately 20 students from the faculty of health sciences to assess the comprehensibility of the statements (items) in terms of language and meaning. As 4 items had similar meanings and/or were not understood, they were removed from the draft list by consensus. The remaining 36 items were rearranged, and thus, the final form was obtained (Table 1).

\section{Scoring of the scale}

Each item in the scale was rated as "strongly agree", "agree", "neutral", "disagree", and "strongly disagree". Positive items were scored from 1 to 5 , starting with the "strongly agree" option, while negative items were scored from 5 to 1 , starting with the "strongly agree" option. As the item "fat people are ordinary people" was 


\begin{tabular}{|c|c|c|c|c|c|c|c|}
\hline $\begin{array}{c}\text { old } \\
\text { item } \\
\text { no }\end{array}$ & $\begin{array}{c}\text { New } \\
\text { item no }\end{array}$ & $\begin{array}{l}\text { Read the following statements and } \\
\text { mark the most appropriate option }(\sqrt{ }) \text { for you. } \\
\text { Obese individuals .............................. }\end{array}$ & $\begin{array}{l}\text { Strongly } \\
\text { agree }\end{array}$ & Agree & Neutral & Disagree & $\begin{array}{l}\text { Strongly } \\
\text { disagree }\end{array}$ \\
\hline 1 & ... & Are Ordinary People & & & & & \\
\hline 2 & 1 & Are Selfish & & & & & \\
\hline 3 & 2 & Have Beautiful Face & & & & & \\
\hline 4 & $\ldots$ & Have Difficulty Doing Clothes Shopping*** & & & & & \\
\hline 5 & 3 & Are Not Aesthetic & & & & & \\
\hline 6 & 4 & Are Smiling & & & & & \\
\hline 7 & $\ldots$ & Are Sensitive ${ }^{* * *}$ & & & & & \\
\hline 8 & 5 & Weak-Minded & & & & & \\
\hline 9 & 6 & Are Susceptible To Diseases & & & & & \\
\hline 10 & 7 & Are Happy & & & & & \\
\hline 11 & 8 & Don't Like To Eat In Society & & & & & \\
\hline 12 & 9 & Are Cowards & & & & & \\
\hline 13 & 10 & Are Hospitable & & & & & \\
\hline 14 & 11 & Are Attractive & & & & & \\
\hline 15 & 12 & Have Limited Mobility & & & & & \\
\hline 16 & $\ldots$ & Don't See Themselves As Fat*** & & & & & \\
\hline 17 & 13 & Smell of Sweat & & & & & \\
\hline 18 & 14 & Are Sympathetic & & & & & \\
\hline 19 & 15 & Look Healthy & & & & & \\
\hline 20 & 16 & Don't Like Moving & & & & & \\
\hline 21 & 17 & Are Confident & & & & & \\
\hline 22 & 18 & Have Low Quality of Life & & & & & \\
\hline 23 & 19 & Look Older Than They Are & & & & & \\
\hline 24 & 20 & Have Strong Social Relations & & & & & \\
\hline 25 & 21 & Get Tired Quickly & & & & & \\
\hline 26 & $\ldots$ & Are Fond of Dessert*** & & & & & \\
\hline 27 & 22 & Are Good Listeners & & & & & \\
\hline 28 & 23 & Are Slow in Their Motions & & & & & \\
\hline 29 & 24 & Are Lazy & & & & & \\
\hline 30 & 25 & Cook Well & & & & & \\
\hline 31 & $\ldots$ & Are Subjected to the Thin Body Imposition of Society*** & & & & & \\
\hline 32 & $\ldots$ & Are Carefree ${ }^{* * *}$ & & & & & \\
\hline 33 & $\ldots$ & Are Constantly on a Diet*** & & & & & \\
\hline 34 & 26 & $\begin{array}{l}\text { Are Not Preferred in Romantic Relationships Because of their } \\
\text { Appearance }\end{array}$ & & & & & \\
\hline 35 & 27 & Are Friendly & & & & & \\
\hline 36 & $\ldots$ & Like Eating $^{* * *}$ & & & & & \\
\hline
\end{tabular}

Table 1: Obesity Bias Scale.

*** Items removed from the scale as a result of the item analysis.

Negative items no: 1, 3, 5, 6, 8, 9, 12, 13, 16, 18, 19, 21, 23, 24, 26 (total 15 negative items).

Positive items no: 2, 4, 7, 10, 11, 14, 15, 17, 20, 22, 25, 27 (total 12 positive items). 
complementary to other items on the scale and was not under the influence of any characteristic, it was evaluated separately. At the next stage, the validity and reliability of the remaining 35item "Obesity Bias Scale" were tested with 236 students who were not involved in the preliminary studies and who were enrolled in Health Sciences School of another university.

\section{Pilot study}

In the literature, the sample size in scale development is recommended to be at least 5-10 times the number of items in the scale. Therefore, the trial form of the 35-item scale was piloted to a total of 236 students from all classes enrolled in the Health Sciences Higher School.

\section{Results and Discussion}

Data analysis

The reliability analysis and explanatory factor analysis studies of the research were carried out using SPSS 25.0 statistical software package. Confirmatory factor analysis was performed with IBM AMOS 21 software package.

\section{Reliability of the scale: Item analysis}

The basic strategy of the Likert scale is based on the assumption that all items in the scale measure the same construct (attitudes/ biases/ behaviors, etc.). However, the sole evidence that guarantees that all items measure the same construct in such scales is the conduction of statistical reliability and validity tests and accurate interpretation by experts. On the Likert-type scale, the distribution of scores obtained from an item is assumed to be a quantitative variable constantly. Besides, the response options on the scale are more than two, and there is no single correct answer. Apart from this, one of the main assumptions of this scale is that each item in the scale has a monotonic relationship with the measured attitude/bias. This means that each item measures the same construct. In other words, reliability ensures that the measurement is free of random errors. The reliability of a scale is a kind of prerequisite for its validity. Reliability indicates the consistency of a scale and ensures that it will always yield the same results. If a tool is reliable, it consistently measures the characteristics it intends to measure. Reliability is the property of a measurement tool ensuring that it produces close results in each measurement. This indicates the sustainability of the scale $[15,16]$.
Therefore, it is appropriate to use the "Cronbach's Alpha" coefficient, which is a measure of internal consistency and which is developed by Cronbach, to determine the reliability level on a Likert-type attitude/bias scale. This coefficient is used to examine whether k number of items in the scale form a whole to explain or question a homogeneous structure [15].

Another method of testing the reliability of a scale is to use the reliability coefficient based on the method of dividing the items of a scale into two halves (Split Half Reliability). Once the scale is administered to the same sample group, the sample group is divided into two equivalent halves and the correlation coefficient between the two variables consisting of the sum of the items in both halves is found.

Both reliability coefficients take values between zero and one. According to the cut-off points identified by experts, a coefficient value of 0.39 and lower shows "the scale is unreliable", a value between 0.40 and 0.59 indicates "the scale has poor reliability", a value between 0.60 and 0.79 shows "the scale is reliable", and a value 0.80 or greater means "the scale is highly reliable".

The analysis of the correlations between the total score of an item and the total score of other items except for this item (Corrected Item- Total Correlation) is needed for measuring the construct that the scale aims to measure, determining the measuring power of each item, and making the scale more reliable by utilizing this information. Item-total score correlation should not be negative and less than 0.25 . Exclusion of the items that do not meet this requirement will increase the reliability of the scale $[15,16]$.

The items out of 35 items of the trial form of the five-point Likert-type "Obesity Bias Scale" that was positively correlated with the total scale item score were examined. The results are given in table 2 .

When the reliability analysis was performed on the remaining 35 items without considering the first item in the scale, Cronbach's alpha coefficient of the scale was found to be 0.767 (corrected Cronbach's alpha 0.762). However, as a result of item analysis, items $4,7,16,26,31,32,33$, and 36 were found to be negatively correlated with the total scale score; therefore, they were removed from the scale because they damaged the summability of the scale. 


\begin{tabular}{|c|c|c|c|c|c|c|c|}
\hline Item No & $\mathbf{r}$ & $\begin{array}{c}\text { Item } \\
\text { No }\end{array}$ & $\mathbf{r}$ & $\begin{array}{c}\text { Item } \\
\text { No }\end{array}$ & $\mathbf{r}$ & $\begin{array}{c}\text { Item } \\
\text { No }\end{array}$ & $\mathbf{r}$ \\
\hline 1 & -------- & 11 & 0,299 & 21 & 0,493 & 31 & $-0,073 *$ \\
\hline 2 & 0,239 & 12 & 0,424 & 22 & 0,509 & 32 & $-0,062 *$ \\
\hline 3 & 0,404 & 13 & 0,316 & 23 & 0,371 & 33 & $-0,046^{*}$ \\
\hline 4 & $-0,234 *$ & 14 & 0,525 & 24 & 0,441 & 34 & 0,337 \\
\hline 5 & 0,349 & 15 & 0,409 & 25 & 0,443 & 35 & 0,345 \\
\hline 6 & 0,360 & 16 & $-0,015^{*}$ & 26 & $-0,150 *$ & 36 & $-0,138^{*}$ \\
\hline 7 & $-0,043^{*}$ & 17 & 0,487 & 27 & 0,271 & & \\
\hline 8 & 0,461 & 18 & 0,285 & 28 & 0,541 & & \\
\hline 9 & 0,301 & 19 & 0,408 & 29 & 0,477 & & \\
\hline 10 & 0,509 & 20 & 0,379 & 30 & 0,234 & & \\
\hline $\begin{array}{l}\text { * Items } \\
\text { showing a } \\
\text { negative } \\
\text { correlation } \\
\text { with the total } \\
\text { scale score } \\
\text { were removed } \\
\text { from the scale }\end{array}$ & & & & & & & \\
\hline
\end{tabular}

Table 2: Item-total scale score correlations of the trial form of the obesity bias scale.

When these 8 items were removed from the scale, and the remaining 27 items (15 negatives; 12 positives) were re-analyzed, Cronbach's alpha reliability coefficient was found to increase to 0.847 (corrected Cronbach 0.845 ). This result showed that the scale had a reliable measurement capacity.

The same reliability result was obtained by employing the Split-Half Reliability method. The result of the calculation of Spearman-Brown reliability coefficient $(0.838)$ by dividing the items on the scale into two randomly selected groups using computer software (13 and 14 items) once again confirmed the high reliability of the scale.

Validity of the scale: Explanatory and confirmatory factor analysis

Both the phases followed in the article writing process and the high item-total score test correlation proved that the scale had content validity. Also, explanatory and confirmatory factor analyses were employed to ensure the construct validity of the scale.
If a newly developed scale measures "the feature that it aims to measure" correctly and without confusing it with other features, it is said to be a valid scale. Validity is not an attribute of the measurement tool (scale form); it refers to the results that the tool produces. Validity indicates a level-degree. It is not appropriate to say that a tool has or does not have validity; rather, it is more plausible to say "the reliability level of the results of the measuring tool is low/high. "Reliability" is necessary but not adequate for validity because a measuring tool can always give the same result, but it may measure other things than the desired construct as well. Therefore, Explanatory Factor Analysis, which is one of the multivariate statistical methods, was employed to test the structural validity of the obesity bias scale, and then, Confirmatory Factor Analysis was used to confirm these results. These procedures aimed to select the items among the 35 items on the scale that would make a meaningful whole. In this study, the use of Factor Analysis and Principal Component Factor Analysis estimation method was considered to be more appropriate since the study aimed to reveal empirically existing appropriateness rather than questioning the suitability of the items to a predetermined structure $[15,16]$.

Kaiser-Meyer-Olkin (KMO) coefficient was employed to determine whether the number of samples was adequate for factor analysis. The coefficient was found to be 0.844 , which was considerably higher than the threshold value of 0.5 reported in the literature, and the sample size was sufficient for applying factor analysis. Also, there must be a correlation between the items so that a whole construct can be formed using the related variables. For this reason, Barlett's Sphericity test was used to determine whether the correlations of all items were different from zero. The results indicated that the items were statistically significantly correlated (Chi-square $=2328.348 ; \mathrm{p}=0.000$ ). As a result of the Explanatory Factor Analysis, the items of the scale were observed to exhibit a single factor distribution. The variance explained by the single factor was found to be $44.263 \%$. This variance value was at an acceptable level for a single factor scale. A ratio of higher than $30 \%$, especially in the scales developed in social sciences, is accepted to be adequate. That the explained variance is high can be interpreted as an indication that the related concept or structure is measured quite well $[15,16]$. As a result of the factor analysis, the factor loads were found to vary between 0.419 and 0.71 . The items with a load value higher than 0.40 were decided to remain on the scale (Table 3). 


\begin{tabular}{|l|c|c|c|c|c|}
\hline $\begin{array}{c}\text { One-factor } \\
\text { (dimension) } \\
\text { items }\end{array}$ & $\begin{array}{c}\text { Factor } \\
\text { loads }\end{array}$ & $\begin{array}{c}\text { One-factor } \\
\text { (dimension) } \\
\text { items }\end{array}$ & $\begin{array}{c}\text { Factor } \\
\text { loads }\end{array}$ & $\begin{array}{c}\text { One-factor } \\
\text { (dimension) } \\
\text { items }\end{array}$ & $\begin{array}{c}\text { Factor } \\
\text { loads }\end{array}$ \\
\hline 1 & 0,654 & 11 & 0,546 & 21 & 0,553 \\
\hline 2 & 0,586 & 12 & 0,547 & 22 & 0,528 \\
\hline 3 & 0,438 & 13 & 0,612 & 23 & 0,695 \\
\hline 4 & 0,657 & 14 & 0,691 & 24 & 0,621 \\
\hline 5 & 0,580 & 15 & 0,452 & 25 & 0,610 \\
\hline 6 & 0,419 & 16 & 0,547 & 26 & 0,470 \\
\hline 7 & 0,513 & 17 & 0,519 & 27 & 0,710 \\
\hline 8 & 0,661 & 18 & 0,644 & & \\
\hline 9 & 0,541 & 19 & 0,507 & & \\
\hline 10 & 0,599 & 20 & 0,557 & & \\
\hline
\end{tabular}

Table 3: Factor load values according to the results of the explanatory factor analysis.

As a result of explanatory factor analysis, the obesity bias scale was determined to be composed of 27 items with a single factor (dimension). Whether the one-dimensional obesity bias scale factor model conformed the data was evaluated using confirmatory factor analysis. Different criteria can be used to evaluate the model fit. In this study, given the sample size, Chi-square $\left(\chi^{2}\right)$ goodness was found to have an excellent fit $\left(\chi^{2} / \mathrm{sd}=2.49\right)$. A ratio of $\chi^{2} / \mathrm{sd}$ below 3 corresponds to a perfect fit, while a ratio of less than 5 refers to a moderate level of fit [15]. Here, the $\chi^{2} /$ sd ratio of the obesity scale was found to have a perfect fit. The value of the non-normed fit index (NNFI) (0.92), the value of the comparative fit index (CFI) (0.97), and the value of the root mean square error of approximation (RMSEA) (0.08) indicated that the model fit was good (Table 4).

Assessment of scale score

The highest and the lowest scores that can be obtained from the 27-item Obesity Bias Scale were 135 and 27, respectively. First, the descriptive statistics of the scores obtained from the scale were examined. The mean score of the scale was 76.394 and the median was 76. As for the percentiles of the scores, the $5^{\text {th }}$ percentile corresponded to 58 points; the $25^{\text {th }}$ corresponded to 68 ; the $50^{\text {th }}$ corresponded to 76 ; the $75^{\text {th }}$ corresponded to 84 ; and the $95^{\text {th }}$ percentile corresponded to 96 points. The scores corresponding to the percentages are classified as unbiased 68,00 and less (below $25^{\text {th }}$ percentile), prone to be biased $68,01-84,9$ ( $25^{\text {th }}-75^{\text {th }}$ percentile), and biased 85 and greater (above $75^{\text {th }}$ percentile).

\begin{tabular}{|l|c|c|}
\hline Fit Indices & $\begin{array}{c}\text { Evaluation } \\
\text { Criteria }\end{array}$ & $\begin{array}{c}\text { The Single Dimension } \\
\text { (Obesity bias) }\end{array}$ \\
\hline$\chi^{2} / \mathrm{sd}$ & $3<\chi^{2} / \mathrm{sd}<4-5$ & $585,49 / 235=2,49$ \\
\hline NNFI & $0,94-0,90$ & 0,92 \\
\hline CFI & $>0,95$ & 0,97 \\
\hline RMSEA & $0,06-0,08$ & 0,078 \\
\hline
\end{tabular}

Table 4: Confirmatory factor analysis model fit indices and evaluation criteria.

When the scores were examined according to positive and negative items, individuals were found to be unbiased towards obesity as their score decreased, while they were found to be biased towards obesity as their score increased. Distribution of Obesity Bias Scale Scores is appropriate for normal distribution (Kolmogorov-Smirnov Normality Test $\mathrm{p}=0.417$ ). The classification of scale scores was done according to the scores corresponding to the percentiles.

\section{Conclusion}

Both psychological and social problems are on a rapid increase due to biased, discriminatory, and stigmatizing behaviors towards individuals with obesity in all societies. This situation also makes strategies for coping with obesity ineffective and decreases the rate of success. Particularly, healthcare workers play a major role in ensuring that individuals with obesity complete their treatment and have normal health. Therefore, it is necessary to primarily raise awareness of whether health workers have bias against individuals with obesity. In this study, a valid and reliable scale was developed to measure whether individuals receiving health education have obesity biases. Explanatory factor analysis indicated that the scale had a one-dimensional construct and that this single dimension explained $44.263 \%$ of the total variance. That this ratio is higher than $30 \%$ is adequate for a newly developed scale. The high variance explained is a sign that the targeted concept or construct is measured quite well. Confirmatory factor analysis confirmed the one-dimensional construct of the scale. All results obtained in this analysis $\left(\chi^{2} / \mathrm{sd}=2.49\right.$; $\mathrm{NNFI}=0.92 ; \mathrm{CFI}=0.97$; $\left.\mathrm{RMSEA}=0.08\right)$ proved that the scale was one-dimensional. The reliability analysis of the scale was analyzed with item analysis method. Cronbach's alpha and Spearman-Brown reliability coefficients were found to be 0.845 and 0.838 , respectively. These ratios showed that the scale was highly reliable. 
The obesity bias scale consists of 27 items, and the highest and lowest scores that can be obtained from the scale are 135 and 27, respectively. According to the examination of the scores by positive and negative items, decreased total scores obtained from the scale show that individuals are unbiased towards obesity, whereas increased total scores obtained from the scale indicate that individuals are biased towards obesity.

In conclusion, the analyses conducted so far have demonstrated that the obesity bias scale developed in this study is one-dimensional and highly reliable. To make the scale scoring achieve a more sensitive and specific bias categorization, it is recommended that future studies should first find out whether the individuals have true bias, and then determine process characteristic curves and criteria, and the cut-off point.

\section{Conflict of Interest}

There is no conflict of interest.

\section{Bibliography}

1. Darling R and Atav AS. "Attitudes Toward Obese People: A Comparative Study of Nursing, Education, and Social Work Students". Journal of Professional Nursing 35 (2019): 138-146.

2. Wellman JD., et al. "Sex differences in the relationships among weight stigma, depression, and binge eating". Appetite 133 (2019): 166-173.

3. Mason TB., et al. "Stigma control model of dysregulated eating: A momentary maintenance model of dysregulated eating among arginalized/stigmatized individuals". Appetite 132 (2019): 67-72.

4. WHO. "Weight bias and obesity stigma: considerations for the WHO European Region 2017” (2017).

5. WHO. "Obesity and Overweight" (2014).

6. Puhl RM., et al. "Obesity bias in training: attitudes, beliefs and observations among advanced trainees in professional health disciplines". Obesity 22 (2014): 1008-1015.

7. Fuce J., et al. "Dietitians and Nutritionists: Stigma in the Context of Obesity. A Systematic Review". PLoS ONE (Open Access) 10 (2015): 1-16.
8. Salas X R., et al. "Addressing weight bias and discrimination: moving beyond raising awareness to creating change". Obesity Reviews 18 (2017): 1323-1335.

9. Puhl RM and Heuer CA. "Obesitystigma: important considerations for public health". American Journal of Public Health 100.6 (2010): 1019-1028.

10. Fruh SM., et al. "Obesity Stigma and Bias". The Journal for Nurse Practitioners 12.7 (2016): 425-432.

11. Puhl RM and Heuer CA. "The Stigma of Obesity: A Review and Update”. Obesity 17.5 (2009): 941-964.

12. Diedrichs PC and Barlow FK. "How to lose fat bias fast! Evaluating brief anti-weight bias intervention". British Journal of Health Psychology 16 (2011): 846-861.

13. Puhl R., et al. "Weight bias among dietetics students: implications for treatment practices". Journal of the American Dietetic Association 109.3 (2009): 438-444.

14. Puhl R and Brownell KD. "Bias, discrimination and obesity". Obesity Research 9.12 (2001): 788-805.

15. Johnson RA and Wichern DW. "Applied Multivariate Statistical Analysis". $5^{\text {th }}$ edition. Prentice-Hall, INC.USA. (2002).

16. Norman G. "Likert Scales, Levels of Measurement and the "Laws" of Statistics". Advances in Health Sciences Education: Theory and Practice 15 (2010): 625-632.

\section{Assets from publication with us}

- Prompt Acknowledgement after receiving the article

- Thorough Double blinded peer review

- Rapid Publication

- Issue of Publication Certificate

- High visibility of your Published work

Website: www.actascientific.com/

Submit Article: www.actascientific.com/submission.php Email us: editor@actascientific.com

Contact us: +919182824667 